\title{
Pengaruh Kredibilitas Brand Ambassador Terhadap Citra Perusahaan (Studi Kasus Brand Ambassador Shopee Grup K-Pop Stray Kids)
}

\author{
Eva Aileen Frederica ${ }^{1}$, Lusia Savitri Setyo Utami \\ ${ }^{1}$ Fakultas Ilmu Komunikasi, Universitas Tarumanagara, Jakarta \\ Email: eva.915180277@stu.untar.ac.id \\ ${ }^{2}$ Fakultas Ilmu Komunikasi, Universitas Tarumanagara, Jakarta* \\ Email: lusias@fikom.untar.ac.id
}

Masuk tanggal : 15-12-2021, revisi tanggal : 06-01-2022, diterima untuk diterbitkan tanggal : 16-01-2022

\begin{abstract}
The Shopee business relies on promotional content in the form of advertising and employs brand ambassadors as communicators for the messages they want to convey. This brand ambassador is used to give viewers an incentive to attract audience so that they have a positive view of Shopee's corporate image. The Shopee company that collaborated with the well-known K-Pop group Stray Kids as Shopee's brand ambassador at the end of 2020. As a brand ambassador, Stray Kids has managed to steal the attention of the public and K-Pop fans in Indonesia with a Shopee advertisement similar to one of the music video clips. their most famous one is "God's Menu". The purpose of this study was to determine the impact of Stray Kids brand ambassador credibility on Shopee's corporate image. The author uses stimulus response theory as a theoretical reference as well as communication, brand ambassadors, image, and company image as research concepts. This study uses a quantitative approach with an explanatory survey method to 100 respondents as a sample with a google form questionnaire as the author's instrument. With the results of the t-test showing a t-count value of $6.832>t$-table 1.987 and the results of a simple linear regression test with a value of 0.000 $<0.05$, which means that there is a significant effect of the Stray Kids Brand Ambassador Credibility variable $(X)$ on Shopee Company Image $(Y)$.
\end{abstract}

Keywords: brand ambassador, credibility, corporate image, Shopee, Stray Kids

\begin{abstract}
Abstrak
Perusahaan Shopee mengandalkan konten promosi mereka yang berupa iklan dan menggunakan brand ambassador sebagai komunikator pesan yang ingin mereka sampaikan. Brand ambassador ini digunakan dengan tujuan untuk memberikan stimulus kepada khalayak untuk menarik konsumen agar konsumen memiliki pemikiran yang positif terhadap citra perusahaan Shopee. Perusahaan Shopee yang menggandeng grup K-Pop ternama yaitu Stray Kids sebagai brand ambassador Shopee pada akhir tahun 2020. Sebagai brand ambassador, Stray Kids telah berhasil mencuri perhatian masyarakat dan penggemar K-Pop di Indonesia dengan iklan Shopee yang mirip dengan salah satu music video clip mereka yang paling terkenal yaitu "God's Menu". Tujuan dari penelitian ini ialah untuk mengetahui pengaruh antara kredibilitas brand ambassador Stray Kids terhadap citra perusahaan Shopee. Penulis menggunakan teori stimulus respon sebagai acuan teori serta komunikasi, brand ambassador, citra, dan citra perusahaan sebagai konsep penelitian. Penelitian ini menggunakan pendekatan kuantitatif dengan metode survey eksplanatif terhadap 100 responden sebagai sampel dengan kuesioner google form sebagai instrumen penulis. Dengan hasil uji t menunjukkan nilai $t$ hitung yaitu 6,832 > t tabel 1,987 dan hasil uji regresi linear sederhana dengan nilai 0,000<
\end{abstract}


0,05 yang berartikan bahwa terdapat pengaruh yang signifikan dari variabel Kredibilitas Brand Ambassador Stray Kids (X) terhadap Citra Perusahaan Shopee (Y).

Kata Kunci: kredibilitas, brand ambassador, citra perusahaan, Shopee, Stray Kids

\section{Pendahuluan}

Pada saat ini perusahaan-perusahaan sedang berlomba-lomba dalam meningkatkan strategi yang tepat guna mengembangkan bisnis atau perusahaannya, produsen akan memikirkan hal-hal yang kreatif dalam penyebaran informasi sehingga informasi yang disampaikan tersebut dapat melekat pada pikiran para konsumen. Salah satu media dalam penyebaran informasi ialah iklan atau advertising. Iklan merupakan suatu bentuk penyampaian informasi produk maupun jasa melalui suatu media.

Agar pesan iklan dapat selalu diingat oleh konsumen, produsen harus memikirkan cara untuk menarik perhatian para konsumen. Menurut Rizal dan Furinto (2009), cara untuk mempertahankan minat dan perhatian konsumen ialah pesan iklan harus ditata dengan baik, lalu iklan dibuat semenarik mungkin, menghibur, dan tentunya bermanfaat bagi konsumen. Salah satu upaya agar iklan atau perusahaan yang dipromosikan tersebut dapat menarik perhatian pemirsa ialah dengan cara menggunakan brand ambassador. Salah satu perusahaan yang menggunakan strategi ini ialah perusahaan Shopee yang menggandeng grup K-Pop ternama yaitu Stray Kids pada akhir tahun 2020 sebagai brand ambassador perusahaan mereka. Strategi perusahaan saat ini bekerja sama dengan brand ambassador adalah untuk menyampaikan produk dan layanan serta membentuk identitas perusahaan.

Menurut John R.Rossiter (2014), terdapat faktor-faktor penting yang perlu diperhatikan agar brand ambassador dapat bermanfaat bagi perusahaan/produk yang diiklankan, faktor tersebut dikenal dengan model VisCAP yang terdiri dari Visibility, Credibility, Attraction dan Power. Visibility merupakan tingkat kepopularitasan selebriti tersebut. Credibility merupakan tingkat pengetahuan selebriti tersebut dalam produk atau brand yang akan dipasarkan. Attraction merupakan karisma atau aura dari dalam diri selebriti tersebut. Power merupakan Power atau kekuasaan merupakan kekuatan dari dalam diri selebriti tersebut dalam menarik perhatian khalayak.

Sebagai brand ambassador, Stray Kids telah berhasil mencuri perhatian masyarakat dan penggemar K-Pop dengan iklan Shopee yang mirip dengan salah satu music video clip mereka yang paling terkenal yaitu "God's Menu". Hal ini dapat menjadi salah satu faktor Shopee dapat diingat atau diketahui lebih luas oleh masyarakat dan dapat mempengaruhi pandangan masyarakat pada citra perusahaan Shopee.

Menurut Jeffkins (2003), citra perusahaan adalah citra diri dari suatu organisasi/perusahaan secara keseluruhan. Citra perusahaan merupakan suatu hal yang akan terus melekat dalam ingatan konsumen. Hal yang positif dapat meningkatkan citra perusahaan, misalnya melalui keberhasilan perusahaan atau event yang dilakukan oleh perusahaan tersebut. Menurut Andressen dalam Aryani (2019), terdapat faktorfaktor yang membentuk citra perusahaan yaitu Advertising (Periklanan), Public Relations, Physical Image (Gambaran Fisik), dan Actual Experience (Pengalaman Nyata).

Teori Stimulus-Organisasi-Respon (S-O-R) adalah model komunikasi sederhana dimana efeknya merupakan respon terhadap stimulus tertentu (Mulyana, 2005). Menurut teori ini, efek pihak pertama pada dasarnya adalah respons spesifik 
terhadap stimulus tertentu. Oleh karena itu, luas dan metode efek sepenuhnya bergantung pada isi dan penyajian stimulus (Sendjaja, 2004). Dengan menggunakan teori ini, penulis ingin melihat inspirasi yang terjadi pada khalayak ketika bereaksi terhadap brand ambassador dan citra perusahaan Shopee.

Mengingat latar belakang di atas, masalah penyelidikan ini mengarah pada kesimpulan berikut. Seberapa besar kredibilitas brand ambassador Stray Kids mempengaruhi citra perusahaan Shopee? Oleh karena itu, tujuan dari penelitian ini adalah untuk mengetahui bagaimana brand ambassador Stray Kids mempengaruhi citra perusahaan Shopee.

\section{Metode Penelitian}

Dalam penelitian ini penulis menggunakan metode kuantitatif eksplanatif survei. Populasi penelitian dalam penelitian ini ialah pengguna aktif aplikasi Shopee yang diasumsikan sebanyak 834.520.000 pengguna per bulan Agutus 2021 (Teknologi.bisnis.com, 2021). Teknik pengambilan sampel yang digunakan oleh penulis ialah nonprobability sampling. Nonprobability sampling adalah teknik pengambilan sampel dengan tidak memberikan kesempatan yang sama kepada semua populasi sebagai sampel (Sugiyono, 2015). Adapula teknik untuk menentukan sampel yang dipakai penulis. Teknik penentuan sampel yang digunakan penulis yaitu purposive sampling.

Menurut Sugiyono dalam Fortunata \& Utami(2021), purposive sampling yaitu teknik pengambilan sampel berdasarkan kriteria khusus yang telah dipertimbangkan oleh penulis. Pendekatan purposive sampling yang digunakan penulis guna mendapatkan sampel yang memenuhi kriteria yang ditetapkan oleh penulis ialah masyarakat yang menggunakan aplikasi Shopee (user aplikasi Shopee), mengetahui brand ambassador Shopee yang sedang diteliti yakni Stray Kids, berusia 15 sampai dengan 35 tahun. Teknik penarikan sampel yang akan digunakan dalam penelitian ini yaitu menggunakan pendekatan rumus Slovin. Hasil dari perhitungan sampel penelitian dengan menggunakan rumus Slovin yaitu 99,99 dibulatkan menjadi 100 responden sebagai sampel yang mewakili dari 834.520.000 pengguna aplikasi Shopee. Dalam penelitian ini, untuk pengumpulan data penulis menggunakan beberapa cara yaitu dengan cara menyebarkan kuesioner dengan bentuk google form dengan skala likert yang akan disebarkan melalui internet dan media sosial, melalui buku-buku referensi, jurnal online, situs online, dan referensi skripsi penelitian terdahulu.

Metode analisis data yang digunakan penulis dalam penelitian ini adalah uji-t dan analisis regresi linier sederhana. Lalu, untuk menguji keabsahan data penulis menggunakan uji normalitas, uji validitas, dan uji reliabilitas.

\section{Hasil Temuan dan Diskusi}

Berdasarkan hasil kuesioner yang disebarkan oleh penulis kepada pengguna aktif aplikasi Shopee, penulis mendapat identitas responden berupa usia responden, jenis kelamin responden, pengguna aktif aplikasi Shopee, dan mengetahui boygroup Stray Kids. Jumlah mayoritas rentang usia responden yaitu 21 tahun - 25 tahun sebanyak 68 orang dengan presentase $68 \%$. Jumlah mayoritas jenis kelamin responden yaitu perempuan sebanyak 86 orang dengan presentase $86 \%$. Jumlah mayoritas responden yang menjadi pengguna aktif aplikasi Shopee yaitu 100 orang dengan presentase $100 \%$. Lalu, jumlah mayoritas responden yang mengetahui boygroup Stray Kids yaitu 99 orang dengan presentase $99 \%$. 
Penelitian ini memiliki 29 item pernyataan yang terdiri dari 16 item pernyataan variabel X (Kredibilitas Brand Ambassador) dan 13 butir pernyataan variabel Y (Citra Perusahaan Shopee).

\section{Uji Validitas}

Tabel 1. Hasil Uji Validitas Variabel X (Kredibilitas Brand Ambassador)

\begin{tabular}{|c|c|c|c|}
\hline Variabel & Nilai R Hitung & Nilai R Tabel & Keterangan \\
\hline $\mathrm{X} \_1 \_1.1$ & 0,717 & 0.195 & Valid \\
\hline $\mathrm{x} \_1 \_1.2$ & 0,656 & 0.195 & Valid \\
\hline$x \_1 \_1.3$ & 0,658 & 0.195 & Valid \\
\hline x_1_2.1 & 0,729 & 0.195 & Valid \\
\hline $\mathrm{x} \_2 \_1.1$ & 0,772 & 0.195 & Valid \\
\hline x_2_2.1 & 0,849 & 0.195 & Valid \\
\hline$x \_2 \_2.2$ & 0,851 & 0.195 & Valid \\
\hline x_2_2.3 & 0,696 & 0.195 & Valid \\
\hline $\mathrm{x} \_3 \_1.1$ & 0,819 & 0.195 & Valid \\
\hline x_3_2.1 & 0,791 & 0.195 & Valid \\
\hline $\mathrm{x} \_4 \_1.1$ & 0,841 & 0.195 & Valid \\
\hline X_4_ 1.2 & 0,636 & 0.195 & Valid \\
\hline X_4_2.1 & 0,506 & 0.195 & Valid \\
\hline $\mathrm{x} \_4 \_2.2$ & 0,763 & 0.195 & Valid \\
\hline x_4_2.3 & 0,744 & 0.195 & Valid \\
\hline x_4_ 2.4 & 0,524 & 0.195 & Valid \\
\hline
\end{tabular}

Sumber: Pengolahan data SPSS 22.

Tabel 2. Hasil Uji Validitas Variabel Y (Citra Perusahaan)

\begin{tabular}{cccc}
\hline Variabel & Nilai R Hitung & Nilai R Tabel & Keterangan \\
\hline y_1_1.1 & 0,658 & 0.195 & Valid \\
\hline y_1_2.1 & 0,678 & 0.195 & Valid \\
\hline y_2_1.1 & 0,824 & 0.195 & Valid \\
\hline y_2_1.2 & 0,819 & 0.195 & Valid \\
\hline y_2_2.1 & 0,699 & 0.195 & Valid \\
\hline y_3_1.1 & 0,726 & 0.195 & Valid \\
\hline y_3_1.2 & 0,744 & 0.195 & Valid \\
\hline y_3_1.3 & 0,787 & 0.195 & Valid \\
\hline y_3_1.4 & 0,627 & 0.195 & Valid \\
\hline y_4_1.1 & 0,785 & 0.195 & Valid \\
\hline y_4_1.2 & 0,768 & 0.195 & Valid \\
\hline y_4_2.1 & 0,747 & 0.195 & Valid \\
\hline y_4_2.2 & 0,767 & 0.195 & Valid
\end{tabular}

Sumber: Pengolahan data SPSS 22.

Dari tabel 3.1 dan 3.2, hasil validasi variabel X dan Y menunjukkan bahwa semua item pernyataan untuk variabel X (kredibilitas brand ambassador) dan Y (citra perusahaan) telah dinyatakan valid, hal tersebut dapat dilihat dari pernyataan responden yang memiliki $r$ lebih banyak daripada $r$ tabel. 


\section{Uji Reliabilitas}

TabeI 3. Hasil Uji Reliabilitas Variabel X (Kredibilitas Brand Ambassador)

\begin{tabular}{cr}
\hline \multicolumn{2}{c}{ Reliability Statistics } \\
\hline $\begin{array}{c}\text { Cronbach's } \\
\text { Alpha }\end{array}$ & $\mathrm{N}$ of Items \\
\hline .937 & 16 \\
\hline
\end{tabular}

Sumber: Pengolahan data dengan SPSS 22.

Tabel 4. Hasil Uji Reliabilitas Variabel Y (Citra Perusahaan)

\begin{tabular}{cr}
\hline \multicolumn{2}{c}{ Reliability Statistics } \\
\hline $\begin{array}{c}\text { Cronbach's } \\
\text { Alpha }\end{array}$ & N of Items \\
\hline .930 & 13 \\
\hline
\end{tabular}

Sumber: Pengolahan data SPSS 22.

Dari tabel 3.3 dan 3.4, hasil dari uji reliabilitas variabel $\mathrm{X}$ dan variabel $\mathrm{Y}$ menyatakan seluruh butir pernyataan variabel X (Kredibilitas Brand Ambassador) dan variabel Y (Citra Perusahaan) dinyatakan reliabel dikarenakan memiliki nilai Cronbanch's Alpha sebesar 0,937 \& 0,930 yang berartikan variabel X dan variabel $\mathrm{Y}$ memiliki angka Cronbanch's Alpha lebih besar dari 0,6.

\section{Uji Normalitas}

Tabel 5. Hasil Uji Normalitas

\begin{tabular}{llr}
\hline \multicolumn{3}{c}{ One-Sample Kolmogorov-Smirnov Test } \\
\hline $\mathrm{N}$ & $\begin{array}{r}\text { Unstandardiz } \\
\text { ed Residual }\end{array}$ \\
\hline Normal Parameters ${ }^{\text {a,b }}$ & Mean & 100 \\
\cline { 2 - 3 } & $\begin{array}{l}\text { Std. } \\
\text { Deviation }\end{array}$ & 5.56156032 \\
\hline Most Extreme & Absolute & .104 \\
\cline { 2 - 3 } Differences & Positive & .074 \\
\cline { 2 - 3 } & Negative & -.104 \\
\hline Test Statistic & & .104 \\
\hline Exact Sig. (2-tailed) & & .211 \\
\hline Point Probability & .000 \\
\hline a. Test distribution is Normal. & \\
\hline b. Calculated from data. & \\
\hline \multicolumn{2}{c}{ c. Lilliefors Significance Correction. } \\
\hline \multicolumn{2}{c}{ Sumber: Pengolahan data SPSS 22. } \\
\hline
\end{tabular}

Dapat dilihat dari tabel 3.5, hasil uji normalitas menunjukkan nilai signifikansi dalam penelitian ini ialah sebesar 0,211 yang berartikan bahwa nilai tersebut lebih besar dari 0,05. Hal ini dapat disimpulkan bahwa variabel X ( Kredibilitas Brand Ambassador ) dan variabel Y ( Citra Perusahaan ) berdistribusi normal. 


\section{Analisis Regresi Sederhana}

Tabel 6. Hasil Analisis Regresi Linear Sederhana

\begin{tabular}{|c|c|c|c|c|c|c|}
\hline \multicolumn{7}{|c|}{ Coefficients $^{a}$} \\
\hline \multirow{2}{*}{\multicolumn{2}{|c|}{ Model }} & \multicolumn{2}{|c|}{$\begin{array}{l}\text { Unstandardized } \\
\text { Coefficients }\end{array}$} & \multirow{2}{*}{$\begin{array}{c}\text { Standardized } \\
\text { Coefficients } \\
\text { Beta }\end{array}$} & \multirow[b]{2}{*}{$\mathrm{t}$} & \multirow[b]{2}{*}{ Sig. } \\
\hline & & B & Std. Error & & & \\
\hline 1 & (Constant) & 23.232 & 4.981 & & 4.664 & .000 \\
\hline & $\begin{array}{l}\text { Kredibilitas Brand } \\
\text { Ambassador }\end{array}$ & .498 & .073 & .568 & 6.832 & .000 \\
\hline
\end{tabular}

a. Dependent Variable: Citra Perusahaan

Sumber: Pengolahan data SPSS 22.

Dapat dilihat dari tabel 3.6, hasil analisis regresi linear sederhana menunjukkan bahwa nilai Constant (a) sebesar 23,232, lalu untuk nilai Kredibilitas Brand Ambassador (b /koefisien regresi) sebesar 0,498, sehingga untuk persamaan regresi nya dapat ditulis dengan $\mathrm{Y}=23,232+0,498 \mathrm{X}$. Berdasarkan tabel Coefficients, dapat dilihat nilai signifikansi yang diperoleh sebesar $0,000<0,05$. Dari sini dapat disimpulkan bahwa terdapat pengaruh yang signifikan pada variabel X ( Kredibilitas Brand Ambassador ) terhadap variabel Y (Citra Perusahaan ).

\section{Uji T}

Tabel 7. Hasil Uji T

\begin{tabular}{|c|c|c|c|c|c|c|}
\hline \multicolumn{7}{|c|}{ Coefficients $^{a}$} \\
\hline \multirow{2}{*}{\multicolumn{2}{|c|}{ Model }} & \multicolumn{2}{|c|}{$\begin{array}{l}\text { Unstandardized } \\
\text { Coefficients }\end{array}$} & \multirow{2}{*}{$\begin{array}{c}\text { Standardized } \\
\text { Coefficients } \\
\text { Beta }\end{array}$} & \multirow[b]{2}{*}{$t$} & \multirow{3}{*}{$\begin{array}{l}\text { Sig. } \\
.000\end{array}$} \\
\hline & & $\mathrm{B}$ & Std. Error & & & \\
\hline 1 & (Constant) & 23.232 & 4.981 & & 4.664 & \\
\hline & $\begin{array}{l}\text { Kredibilitas Brand } \\
\text { Ambassador }\end{array}$ & .498 & .073 & .568 & 6.832 & .000 \\
\hline
\end{tabular}

a. Dependent Variable: Citra Perusahaan

Sumber: Pengolahan data dengan SPSS 22.

Dapat dilihat dari tabel 3.7, hasil uji T menunjukkan hasil pada t tabel tersebut dapat dilihat bahwa, nilai t hitung sebesar 6,832 > t tabel 1,987. sehingga dapat dinyatakan bahwa variabel X (Kredibilitas Brand Ambassador) berpengaruh terhadap variabel Y (Citra Perusahaan).

Berdasarkan hasil analisa data jawaban responden yang telah penulis kumpulkan, dapat disimpulkan bahwa dimensi yang paling berpengaruh pada variabel X (Kredibilitas Brand Ambassador) adalah dimensi Power (Kekuasaan) pada pernyataan tabel 4.17. Hal ini dapat dilihat dari presentase tertinggi responden menjawab sangat setuju pada pernyataan bahwa menurut mereka penting bagi suatu perusahaan memilih secara benar seseorang yang akan dijadikan brand ambassador dengan responden sebanyak 84 orang dengan presentase $84 \%$. Hal ini membuktikan bahwa memilih secara benar seseorang yang akan dijadikan brand ambassador itu sangatlah penting dan memilih seseorang dengan kredibilitas yang tinggi sebagai 
brand ambassador dapat mempengaruhi pandangan khalayak terhadap citra perusahaan yang di promosikan oleh brand ambassador tersebut.

Berdasarkan hasil analisa data jawaban responden yang telah penulis kumpulkan, dapat disimpulkan bahwa dimensi yang paling terpengaruh pada variabel Y (Citra Perusahaan) adalah dimensi Physical Image pada pernyataan tabel 4.29. Hal ini dibuktikan dengan aplikasi Shopee memiliki persentase responden tertinggi yang sepenuhnya menyatakan bahwa aplikasi Shopee merupakan aplikasi e-commerce dengan pengguna terbanyak yaitu 62 responden dengan persentase $62 \%$. Hal ini menjelaskan bahwa dengan adanya dimensi physical image maka, dari bukti fisik yang didapat oleh konsumen atau khalayak dapat memberikan citra diri bagi perusahaan tersebut di mata konsumennya.

Setelah mengumpulkan data kuesioner responden dari responden tentang variabel independen (kredibilitas brand ambassador Stray Kids) dan variabel dependen (citra perusahaan Shopee), dapat dibuat kesimpulan bahwa kredibilitas brand ambassador Stray Kids mempengaruhi citra perusahaan Shopee pada kalangan masyarakat. Hal ini dapat ditunjukkan dengan tanggapan responden yang rata-rata sangat setuju, setuju, dan netral pada pernyataan pertama sampai akhir pernyataan mengenai faktor-faktor penting yang perlu diperhatikan agar brand ambassador dapat bermanfaat bagi perusahaan/produk yang diiklankan, yang dikenal dengan model VisCAP.

Dalam penelitian ini, penulis menggunakan teori stimulus-organisasi-respon. Menurut Effendy dalam Christie \& Paramita (2020), teori SOR atau teori stimulus, respon, organisme adalah teori yang menekankan proses komunikasi dalam stimulus, biologi, teori reaksi, dan bukan lagi metode komunikasi, melainkan metode perubahan sikap. Stimulus yang diberikan oleh perusahaan Shopee melalui bentuk iklan yang disampaikan oleh brand ambassador mereka yaitu Stray Kids menimbulkan persepsi dari masyarakat yang menonton atau melihat sehingga menghadirkan gambaran atau pandangan tentang citra perusahaan Shopee.

Berdasarkan penelitian sebelumnya oleh Rima Nabila Raswen yang berjudul Pengaruh Brand Ambassador Blackpink terhadap Citra Perusahaan Shopee pada Mahasiswi di UIN Suksa Riau telah membuktikan bahwa brand ambassador mempengaruhi citra perusahaan, tetapi bisa menjadi brand ambassador. membantu perusahaan / produk yang diiklankan, yaitu keandalan. Hal ini juga mempengaruhi citra perusahaan.

\section{Simpulan}

Berdasarkan hasil penelitian yang telah dilakukan dan diuji penulis mengenai "Pengaruh Kredibilitas Brand Ambassador terhadap Citra Perusahaan (Studi Kasus Brand Ambassador Shopee Grup K-Pop Stray Kids)", maka penulis dapat menarik kesimpulan yaitu :

1. Penelitian telah menunjukkan bahwa kredibilitas brand ambassador Stray Kids mempengaruhi citra perusahaan Shopee.

2. Dalam penelitian ini, mayoritas responden percaya dengan konten yang dibawakan oleh Stray Kids dikarenakan konsumen beranggapan bahwa Stray Kids cocok menjadi brand ambassador Shopee dan mereka memiliki nilai dan karakter yang sesuai dengan perusahaan Shopee. 
3. Berdasarkan pengaruh kredibilitas brand ambassador terhadap citra perusahaan Shopee, variabel kredibilitas brand ambassador (X) yang paling berpengaruh adalah power (kekuatan).

\section{Ucapan Terima Kasih}

Penulis ingin mengucapkan terima kasih yang sebesar-besarnya kepada seluruh responden yang telah bersedia bekerjasama selama proses pengambilan data. Ucapan terima kasih juga ditujukan kepada pihak lain yang turut membantu penulis.

\section{Daftar Pustaka}

Aryani, L. S. (2019). Pengaruh Brand Ambassador Blackpink Terhadap Citra Perusahaan dan Minat Beli Di Shopee. Doctoral dissertation, Universitas Islam Sultan Agung.

Christie, I. M., \& Paramita, S. (2020). Pengaruh Konten Belajar Online E-Module terhadap Tingkat Pemahaman Partisipan. Koneksi, 5(2), 223-228. http://dx.doi.org/10.24912/kn.v5i2.10249

Fortunata, F., \& Utami, L. S. S. (2021). The Effect of Addiction of Watching Korean Drama Series on Imitation Behavior of Adolescents. Proceedings of the International Conference on Economics, Business, Social, and Humanities (ICEBSH 2021), 570(Icebsh), 876-883. https://doi.org/10.2991/assehr.k.210805.138

Furinto, R. A. (2009). Marketting Reloaded Komplikasi Konsep dan Praktik Pemasaran. Salemba Empat: Jakarta.

Jefkins, F. Y. (2003). Public Relations, Edisi Revisi kelima. Jakarta: Erlangga.

Mulyana, D. (2005). Ilmu Komunikasi Suatu Pengantar. Bandung: Remaja Rosdakarya.

Rossiter, J. R. (2014). 'Branding' explained: Defining and measuring brand awareness and brand attitude. Journal of Brand Management, 21(7), 533-540.

Sendjaja, S. D. (2004). Teori Komunikasi. Jakarta: Penerbit Universitas Terbuka. 